\begin{tabular}{|c|c|c|c|c|}
\hline $\begin{array}{c}\text { 118SHARE: SOCIAL WORK } \\
\text { JURNAL }\end{array}$ & VOLUME: 7 & NOMOR: 1 & HALAMAN: $1-129$ & $\begin{array}{l}\text { ISSN:2339 -0042 }(p) \\
\text { ISSN: } 2528-1577 \\
(e)\end{array}$ \\
\hline
\end{tabular}

\title{
HUMAN TRAFFICKING DI NUSA TENGGARA TIMUR
}

\author{
Oleh \\ Everd Scor Rider Daniel ${ }^{1}$, Nandang Mulyana ${ }^{2}$, Budhi Wibhawa ${ }^{3}$
}

1. Mahasiswa Pasca Sarjana Kesejahteraan Sosial Universitas Padjadjaran

2. Deparmen Kesejahteraan Sosial Universitas Padjadjaran

3. Deparmen Kesejahteraan Sosial Universitas Padjadjaran

Email,

(everd.insight@gmail.com; mulyananandang@yahoo.com; budhi.whibawa@unpad.ac.id )

\begin{abstract}
Abstrak
Gobalisasi yang terjadi di dunia ini menjadikan setiap Negara seolah-olah tidak mempunyai batas lagi. Hal ini disebabkan karena adanya transformasi yang begitu cepat khususnya dalam aspek komunikasi. Globalisasi tidak hanya mempunyai dampat yang positif, tetapi juga berdampak negative, termasuk dalam hal kejahatan. Banyaknya kejahatan yang terjadi saat ini dikarenakan adanya globalisasi.

Salah satu bentuk kejatahan yang disebabkan karena adanya globalisasi adalah human trafficking. Kejataha ini terjadi tidak hanya dalam satu wilayah suatu Negara akan tetapi sudah melewati batas negara. Kejahatan ini melibatkan jaringan internasional. Dengan demikian human trafficking sangat sulit untuk dilacak.

Untuk mengatasi kejahatan human trafficking ini tentunya tidak hanya memberantas mafia yang ada. Intervensi yang paling mudah untuk melawan human trafficking adalah dengan mengatasi factor penyebab masyarakat mudah untuk dijadikan obyek human trafficking. Banyak factor yang menyebabkan masyarakt mudah terjerat human trafficking. Akan tetapi semua factor tersebut bermuara pada masalah kemiskinan. Hal ini terjadi karena human trafficking lebih sering terjadi pada masyarakat yang relative miskin.
\end{abstract}

Kata kunci : globalisasi, human trafficking, kemiskinan

\section{Pendahuluan}

Fenomena globalisasi merupakan salah satu faktor dibalik meluasnya isu-isu kontemporer (modern). Kemajuan teknologi, informasi, yang berkembang pesat menjadi peluang meluasnya jaringan kejahatan, baik bersifat nasional atau transnasional (lintas batas). Globalisasi telah mengaburkan batas-batas negara dan memunculkan persepsi dunia tanpa batas (borderless world) melalui integrasi sosial lintas kultur. Kaburnya batas negara dipandang sebagai salah satu masalah, manusia berpindah-pindah secara bebas tanpa ada hambatan, mobilisasi secara bebas, masif dan praktis telah dipandang sebagai penyebab hadirnya kejahatan.

Globalisasi merupakan suatu bentuk transformasi kemajuan yang didalamnya tidak hanya terjadi proses penyesuaian, tetapi bersinggungan pula terhadap perubahan sosial seperti kemiskinan, pengangguran dan kriminalitas. Proses-proses yang terjadi secara praktis memunculkan pengaruh pada aspek-aspek kehidupan manusia. Cepatnya 
akselerasi dan dinamisasi dalam struktur global dianalisis sebagai ruang transformasi berbagai proses, salah satunya ancaman dan dilema baru, yaitu penguatan terhadap kriminalitas maupun peluang mempertahankan stabilitas kejahatan.

Isu kontemporer yang menjadi pokok pembahasan dalam tulisan ini adalah isu perdagangan manusia (human trafficking). Fenomena ini dipandang sebagai bentuk kejahatan terorganisir yang kompleksitasnya terus meningkat dalam beragam dimensi. Seperti dikutip dari laman soroptimist.org (lembaga internasional bidang kemanusiaan): "Organized crime is largely responsible for the spread of international human trafficking". ${ }^{1}$

Meski secara dimensi waktu, kejahatan ini sudah berlangsung lama, namun dalam prakteknya terus berkembang luas. Kejahatan ini mengalami transformasi model, bentuk, cara-cara terstruktur dan sistematis menuju pola-pola eksploitasi manusia (human exploitation). Berdasarkan dimensi ruang, fenomena perdagangan manusia melibatkan faktor geografis wilayah negara atau umumnya terjadi di wilayah-wilayah perbatasan.

Phil Williams, Director of International Security Studies, University of Pittsburgh, dalam pembahasan the explosion of transnational crime in a globalized world mengungkapkan:

"Transnational criminals have been one of the biggest beneficiaries of globalization. Globalization facilitates international trade but also increases the difficulty of regulating global trade, he says; traffickers and smugglers have exploited this. Williams adds that globalization has increased

1 "Sex Slavery/Trafficking," dalam http://www.soroptimist.org/trafficking/faq.html, diakses tanggal 5 November 2016 inequality around the globe, and that "its disruptive effect has actually caused people to have to go into organized crime and operate in illicit markets as coping mechanisms". ${ }^{2}$

Williams berpandangan, fenomena globalisasi telah mendatangkan suatu manfaat dan keuntungan signifikan bagi para pelaku kriminal. Secara sosiologis, para pelaku perdagangan dan penyelundupan manusia memanfaatkan peluang ini untuk mengekploitasi keuntungan yang ada dibalik perkembangan globalisasi. Gejala ketimpangan akibat globalisasi menjadi faktor penyebab munculnya kejahatan dan mendorong orang-orang terjun ke dalam kejahatan terorganisir dan beroperasi di pasar gelap.

\section{Tinjauan Konseptual}

\section{a. Pengertian Human Trafficking}

Fenomena human trafficking (perdagangan manusia) merupakan salah satu masalah kontemporer yang tengah mendapat perhatian serius. Karakteristiknya bersifat represif dengan tujuan eksploitasi manusia (individu atau kelompok). Luasnya pengaruh dan dampak ancaman yang ditimbulkan, membuat isu human trafficking diklasifikasikan sebagai bentuk kejahatan luar biasa (extra ordinary crime).

Pasal 1 Undang-Undang Nomor 21 Tahun 2007 tentang Pemberantasan Tindak Pidana Perdagangan Orang (PTPPO) mendefenisikan human traficcking sebagai tindakan perekrutan, penampungan, pengangkutan, pengiriman, pemindahan atau penerimaan seseorang. ${ }^{3}$ Modus sindikat perdagangan manusia termanifestasi dalam beragam bentuk yaitu

\footnotetext{
${ }^{3}$ Farhana, Aspek Hukum Perdagangan Orang di Indonesia, Sinar Grafika, Jakarta, 2010.
} 
penculikan, penggunaan kekerasan, penyekapan, penipuan, pemalsuan, penyalahgunaan kekuasaan, memberi bayaran hingga penjeratan utang. Secara sederhana, perdagangan manusia dapat dipahami sebagai suatu bentuk intimidasi terhadap nilai dan kebebasan hak-hak dasar manusia.

Definisi human trafficking menurut Protokol Palermo Perserikatan BangsaBangsa:

"Human Trafficking/Trafficking in persons shall mean the recruitment, transportation, transfer, harboring or receipt of persons, by means of the threat or use of force or other forms of coercion, of abduction, of fraud, of the abuse of power or of a position of vulnerability or of the giving or receiving of payments or benefits to achieve the consent of a person having control over another person for the purpose of exploitation". 4

\section{Human Rights Protocol} Perserikatan Bangsa-Bangsa (PBB), Pasal 3 , menyebut perdagangan manusia termasuk setiap aksi perekrutan, pengangkutan, pemindahan, penerimaan, penjualan, atau pembelian manusia melalui paksaan, penipuan, pembohongan, atau taktik dengan tujuan menempatkan korban dalam kondisi kerja paksa, praktek yang menyerupai perbudakan atau penghambaan. Kondisi kejahatan terjadi ketika tenaga kerja (korban) diperoleh dengan cara paksaan fisik atau non-fisik, pemerasan, pembohongan, penipuan, ancaman atau penggunaan kekerasan fisik dan tekanan psikologis. ${ }^{5}$

\section{b. Human Trafficking di Indonesia}

\footnotetext{
4 "Praktek Perdagangan Manusia dan Permasalahannya Ditinjau dari Sosiologi Hukum," dalam http://bp3akb.jabarprov.go.id/praktekperdagangan-manusia-dan-permasalahannyaditinjau-dari-sosiologi-hukum/, diakses tanggal 3 November 2016
}

Berdasarkan penelusuran literatur, dimensi perdagangan manusia terus meluas hingga menyentuh sendi-sendi kehidupan sosial masyarakat Indonesia.

\section{Tabel Human Trafficking Global dan Nasional}

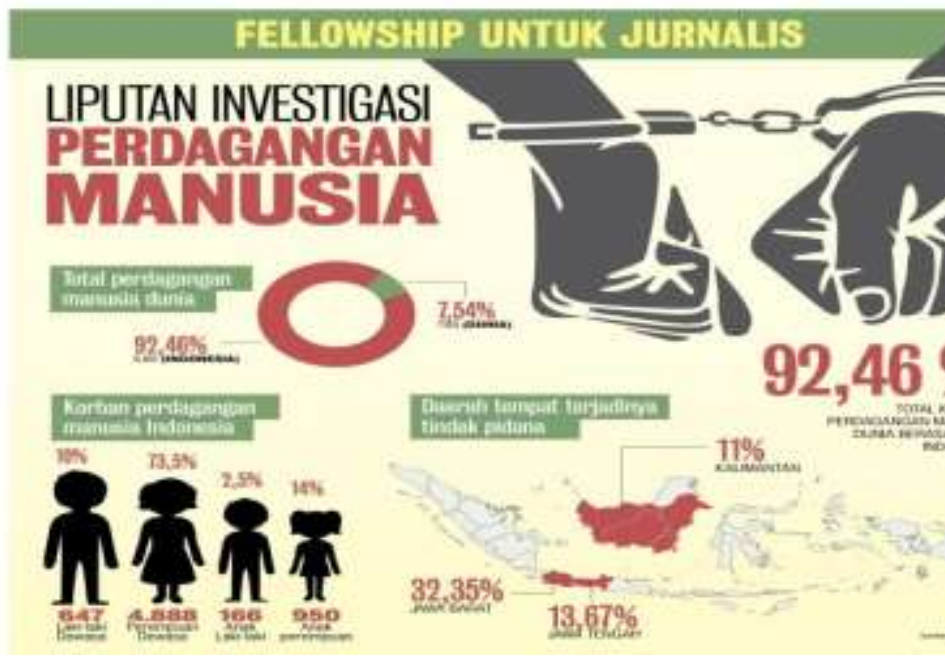

\section{Sumber: Data IOM 2014}

International Organization for Migration (IOM) mencatat, pada periode Maret 2005 hingga Desember 2014, jumlah human trafficking di Indonesia mencapai 6.651 orang. Dari jumlah itu, 82 persen adalah perempuan yang bekerja di dalam dan di luar negeri sebagai tenaga kerja informal dan 18 persen merupakan laki-laki yang mayoritas mengalami eksploitasi ketika bekerja sebagai Anak Buah Kapal $(\mathrm{ABK}){ }^{6}$

Dikutip dari Serikat Pekerja Indonesia Luar Negeri (SPILN) tahun 2015, mayoritas korban sindikat perdagangan manusia didominasi kelompok Buruh Migran Indonesia (BMI) yang lazimnya dikenal sebagai Tenaga Kerja Indonesia (TKI). Faktor utama yang menyeret para pekerja adalah masalah

\footnotetext{
5 Human Rights Watch, Seolah Saya bukan Manusia, 2008, hal. 47

6"Fellowship untuk Jurnalis: Liputan Investigasi Perdagangan Manusia," dalam http://jaring.id/id/enactivities/fellowship/fellowship -untuk-jurnalis-liputan-investigasi-perdaganganmanusia/, diakses tanggal 4 November 2016
} 
ekonomi. Dalam segala keterbatasan, para migran kerap secara mudah dipengaruhi iming-iming kesejahteraan oleh oknum atau mafia kejahatan perdagangan orang. Konteks kejahatan perdagangan manusia menimbulkan kekhawatiran. Ancaman dan resikonya menjadi gejala sosial yang mulai jamak di masyarakat.

\section{c. Human Trafficking di Nusa Tenggara Timur}

Bahaya human trafficking semakin menggejala hingga ke daerah. Salah satu daerah yang menjadi objek kajian dalam pembahasan ini adalah Propinsi Nusa Tenggara Timur (NTT). Kejahatan dan ancaman human trafficking tengah menjadi isu aktual di NTT. Dalam beberapa tahun terakhir, NTT menempati rangking teratas, didaulat sebagai daerah asal korban tindak pidana perdagangan manusia.

Upaya pemberantasan perdagangan orang di NTT tetap menjadi sorotan oleh berbagai macam kalangan. Kemensos RI, memberi sinyal bahwa permasalahan TKI di NTT sudah mencapai kondisi kronis, sehingga langkah penanganan menjadi urgensi bersama. Secara umum, jumlah buruh migran dari NTT bukan yang terbanyak di Indonesia, tetapi angka kasus human trafficking dari NTT menurut data Bareskrim Polri tertinggi di Indonesia. Sejak Februari 2014, kasus perdagangan orang telah menjadi 'titik api' protes gerakan masyarakat sipil di NTT. ${ }^{7}$

Human trafficking di NTT dapat dikatakan sudah darurat karena banyak sekali warga NTT terutama kaum wanita berumur 15 tahun ke atas yang dijadikan TKW ke luar negeri, khususnya Malaysia, Singapura, Taiwan, dan negara-negara lain. Data Institute of Resource Governance and Social Change (IRGSC) bulan Januari sampai Desember 2015, terdapat 941 orang

7 "Data Perdagangan Orang Oktober 2014," dalam http://www.irgsc.org/files/Oktober2014FINAL.pdf, diakses tanggal 3 November 2016

${ }^{8}$ Ibid menjadi korban, disinyalir ada tujuh jaringan perusahaan dan perorangan yang terlibat. Tahun 2015 terdapat $1.667 \mathrm{TKW}$ asal NTT yang menjadi korban human trafficking. Sementara, pada 2016, bulan Januari sampai Juli, ada sekitar 726 TKW yang masalah atau terindikasi praktek perdagangan manusia. ${ }^{8}$

Kepolisian Daerah (Polda) Nusa Tenggara Timur (NTT) mencatat, 1.667 orang calon tenaga kerja wanita (TKW) asal NTT dikirim keluar daerah secara illegal. Para calon TKW rencananya akan dikirim oleh sejumlah jaringan perdagangan manusia untuk bekerja di Medan dan Malaysia. ${ }^{9}$ Dengan kondisi ini, praktek human trafficking menjadi fenomena baru yang cukup mengejutkan karena sebelumnya, secara nasional, NTT belum pernah masuk dalam peringkat tertinggi daftar kasus human trafficking di Indonesia.

\section{Metode}

Kajian ini menggunakan data sekunder yang didasarkan kepada studi dokumentasi dan pustaka. Studi dokumentasi lebih diarahkan untuk mengkaji dan menganalisis hasil laporan serta data yang telah dipublikasikan yang berkaitan dengan fenomena yang dikaji. Sementara itu studi pustaka lebih diarahkan untuk menganlisis fenomena yang ada didasarkan kepada konsep atau teori yang sesuai dengan fenomena yang dikaji

\section{Intervensi terhadap Human Trafficking}

\section{a. Faktor Penyebab terjadinya Human Trafficking}

Terdapat aspek universal dibalik masalah human trafficking yang dialami

\footnotetext{
9"1.667 Calon TKW Asal NTT Jadi Korban "Human Trafficking", dalam http://regional.kompas.com/read/2016/08/23/09090 061/1.667.Calon.TKW.Asal.NTT.Jadi.Korban.Hu man.Trafficking., diakses tanggal 3 November 2016
} 
negara-negara di seluruh dunia. Penyebabnya adalah: poverty, globalization, the sex tourism industry, women's rights, and general global education levels. ${ }^{10}$ Korban trafficking adalah mereka yang terpinggirkan, terutama kaum perempuan (kondisi kemiskinan dan ketidakmandirian yang mereka alami). Kondisi-kondisi psikologis dan masalah kemiskinan secara sistematis mendorong individu untuk melakukan apapun untuk memenuhi kebutuhan hidupnya. Berikut adalah faktor-faktor yang dipandang sebagai penyebab terjadinya masalah human trafficking seperti yang diilustrasikan oleh Cameron \& Newmann, 2008:3.

Tabel 1.1

\section{Faktor-Faktor Penyebab Human Trafficking}

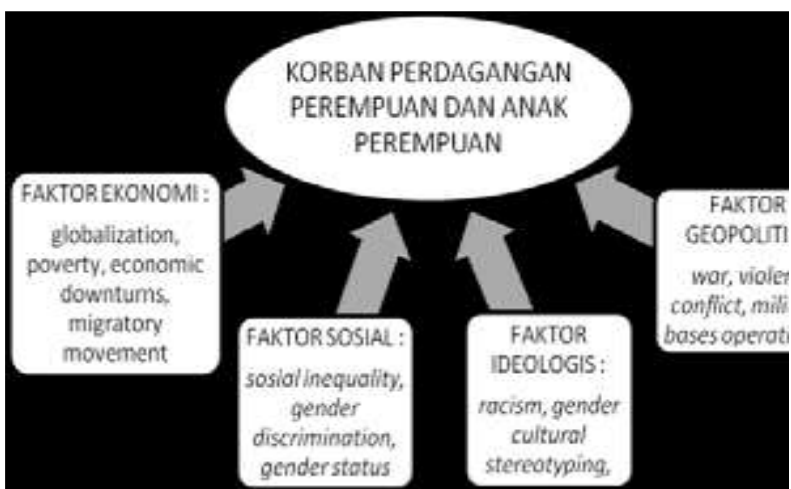

Sumber: Cameron \& Newmann, 2008:3

\section{Kemiskinan}

Kemiskinan termasuk faktor utama yang mendorong orang untuk melakukan apapun agar keluar dari keterbatasan yang dialami. Berikut gambaran umum mengenai tiga aspek kemiskinan; To

\footnotetext{
${ }^{10}$ Diana Betz, Thesis, Human Trafficking in Southeast Asia: Causes and Policy Implications, Naval Postgraduate School, California, 2009, hal. 12-13, dalam http://www.dtic.mil/dtic/tr/fulltext/u2/a501444.pdf, diakses tanggal 3 November 2016

${ }^{11}$ Ibid
}

understand how this universal issue acts as a cause, it is important to examine three specific aspects of poverty: the supply side, the demand side, and the interaction between these two forces. ${ }^{11}$

Supply side (sisi pasokan) dipengaruhi faktor kemiskinan yang dialami individu (keterbatasan sarana dan akses kebutuhan hidup). Sisi permintaan (demand side) mengacu pada industri komersial atau kegiatan yang mengandalkan kemiskinan sebagai komoditas (individu diperdagangkan secara ilegal) dengan tujuan mempertahankan profit atau keuntungan. Berbagai pandangan lembaga atau organisasi secara mayoritas menyebut, faktor utama dan akar penyebab perdagangan manusia adalah dipengaruhi supply side akibat dari kemiskinan. ${ }^{12}$

Faktor kemiskinan mendorong jutaan orang Indonesia melakukan migrasi, domestik maupun internasional yang dipandang sebagai sebuah cara memperoleh kehidupan yang baik bagi dirinya dan keluarga. ${ }^{13}$ Berdasarkan hasil riset, sebuah studi di 41 negara menunjukkan bahwa keinginan untuk meningkatkan kondisi ekonomi dan kurangnya kesempatan kerja adalah salah satu alasan utama wanita mencari pekerjaan di luar negeri (Wijers and Lap-Chew, 1999: 61). Researchers in Indonesia also report that the primary motivation for most workers to migrate is economic (Hugo, 2002: 173; Suryakusuma, 1999:7).

Maraknya perdagangan manusia di Nusa Tenggara Timur (NTT) disinyalir lantaran kemisikinan yang melanda wilayah bagian timur Indonesia itu. Direktur Eksekutif Migrant Care Anis

\footnotetext{
${ }^{12}$ Ruta Tumenaite, Rise in Human Trafficking Tied to Poverty, International Church Conference Participants Say," Catholic Online, October 23, 2006.

13 "Factors that Lead to Trafficking: Poverty," dalam http://www.solidaritycenter.org/wpcontent/uploads/2015/02/IndoTraffickingCOMPIL ED-1.pdf, diakses tanggal 3 November 2016
} 
Hidayah, mengatakan dengan alasan itu perempuan menjadi sasaran empuk yang dijadikan korban untuk "dilego" ke luar negeri. ${ }^{14}$

Kasus perdagangan manusia di NTT muncul sebagai konsekuensi kemiskinan dan minimnya akses kesejahteraan. Ketimpangan dan gejala kemiskinan di NTT memunculkan masalah bagi hak-hak perempuan di NTT, mereka dituntut untuk memperbaiki kondisi ekonomi. Pada kondisi ini, mereka semakin tertekan dan mudah terpengaruh oleh resiko kejahatan.

Kemiskinan merupakan sebuah masalah sosial utama yang terjadi Propinsi NTT. Menurut data Badan Pusat Statistik (BPS) pada September 2014, sekitar 19,6 dari total 4,9 juta populasi NTT tergolong dalam kategori penduduk miskin.

Pengaruh kemiskinan tersebut melahirkan berbagai dampak sosial. Terdapat fakta memprihatinkan, bahwa konsekuensi kemiskinan menempatkan posisi perempuan NTT sebagai pihak yang sangat beresiko terjebak kejahatan, intimidasi, dan eksploitasi praktek perdagangan manusia.

\section{Minimnya Tingkat pendidikan}

Selain faktor ekonomi, rendahnya pemenuhan hak atas akses pendidikan turut melatari munculnya korban kejahatan. Tingginya kasus perdagangan di NTT tidak hanya disebabkan faktor kemiskinan atau ekonomi, tetapi juga pada minimnya tingkat pembangunan Sumber Daya Manusia (SDM) dalam bidang pendidikan.

Mayoritas warga NTT secara ilegal direkrut sebagai TKW-TKI karena tidak memiliki pemahaman akan bahaya dan

\footnotetext{
14"Ini Alasan Utama Maraknya Human Trafficking di NTT," dalam http://news.metrotvnews.com/read/2014/11/24/322 744/ini-alasan-utama-maraknya-human-traffickingdi-ntt, diakses tanggal 7 November 2016
}

resiko. Pengaruhnya pada tingkat pendidikan yang minim, tamat SD atau bahkan tidak bersekolah. Pengetahuan yang minim membuat mereka mudah ditipu dan diperdaya sehingga mudah dijadikan korban human traficking.

Dalam konteks ini, bisa dikatakan kondisi ekonomi yang terbelakang dan SDM yang minim menjadikan NTT sebagai propinsi "Darurat Manusia", orang dengan mudah ditipu akan mendapat kerja yang bagus dan diiming-dimingii gaji yang tinggi. Situasi ini menjadikan NTT sebagai lahan basah bagi para calo. ${ }^{15}$

Studi kasus, seperti dialami Wilfrida Soic, wanita berumur 17 tahun yang hanya mengenyam pendidikan sampai kelas 4 SD. Ia dijadikan korban oleh pelaku dalam hal ini calo, secara terorganisir mengirimnya ke luar negeri, tanpa membawa dokumen apa pun. Dalam kasus ini, paspor Wilfrida difasilitasi dan dibuat di Jakarta kemudian dikirim dari NTT menuju Jakarta dan ke Singapura. ${ }^{16}$

\section{Faktor Ekonomi}

Forrel menyatakan "Traffickers are motivated by money", pelaku perdagangan manusia termotivasi oleh uang. Kalimat ini hendak memberi suatu pemahaman, bahwa faktor ekonomi menjadi salah satu penyebab utama terjadinya kejahatan yang dilatarbelakangi kesenjangan ekonomi, dan lapangan kerja yang tidak memadai dengan besarnya jumlah penduduk. Hal mendesak inilah yang mendorong seseorang mencari pekerjaan meski harus keluar daerah.

Kemiskinan dan rendahnya kesempatan kerja mendorong jutaan penduduk Indonesia melakukan migrasi di

\footnotetext{
15 "NTT, Surga Perdagangan Manusia," dalam http://floresbangkit.com/2015/01/ntt-surgaperdagangan-manusia/, diakses tanggal 3 November 2016

16 Ibid., "Ini Alasan Utama Maraknya Human Trafficking di NTT".
} 
dalam dan keluar negeri guna menemukan cara agar dapat menghidupi diri mereka dan keluarga. Selain kemiskinan, kesenjangan tingkat kesejahteraan antar negara juga menjadi penyebab terjadinya perdagangan manusia. Negara-negara yang tercatat sebagai penerima korban perdagangan manusia dari Indonesia, mayoritas memiliki tingkat kesejahteraan dan ekonomi lebih baik seperti Malaysia, Singapura, Hongkong, Taiwan dan Saudi Arabia. Kesejahteraan ekonomi menjadi tujuan mereka bermigrasi ke negara lain. ${ }^{17}$

\section{Pengangguran}

Pengangguran sebagai salah satu penyebab maraknya korban perdagangan manusia di NTT. Berbagai sumber mencatat, masalah sosial berpengaruh besar terhadap kompleksitas kejahatan di NTT. Beberapa korban adalah mereka yang tidak mampu, atau dikategorikan sebagai kelompok masyarakat rentan.

Agenda forum Seminar Perdagangan Orang yang digelar Komisi Perlindungan Perempuan dan Anak Daerah (KPPAD) Provinsi Bali, Sabtu 29 Oktober 2016, membahas tingginya presentase Kasus Perdagangan Manusia di Nusa Tenggara Timur (NTT). Laporan Serikat Perempuan Indonesia (Seruni), angka pengangguran yang tinggi menjadi salah satu pemicu terjadinya eksodus buruh migran dari NTT. Pada kondisi ini, NTT berada dalam posisi memprihatinkan, angka pengangguran mencapai angka 88 ribu orang. ${ }^{18}$

\footnotetext{
17"Praktek Perdagangan Manusia dan Permasalahannya Ditinjau dari Sosiologi Hukum," dalam http://bp3akb.jabarprov.go.id/praktekperdagangan-manusia-dan-permasalahannyaditinjau-dari-sosiologi-hukum/, diakses tanggal 3 November 2016

18 "KPPAD Bali Soroti Maraknya Kasus Human Trafficking di NTT," dalam https://mikannews.com/2016/10/31/kppad-balisoroti-maraknya-kasus-human-trafficking-di-ntt/, diakses tanggal 7 November 2016
}

Seruni mencatat, terdapat 44 korban meninggal asal NTT akibat tersangkut kasus perdagangan orang. Perempuan muda asal NTT, mudah direkrut perusahaan jasa tenaga kerja menjadi buruh migran. Bahkan, dari penelusuran yang dilakukan, faktor kemiskinan sebagai pendorong sebagian orangtua di NTT mengizinkan anaknya direkrut bekerja di luar negeri. ${ }^{19}$

\section{b. Dampak/Pengaruh Human Trafficking bagi Warga NTT}

Fenomena human trafficking merupakan masalah sosial yang mengganggu stabilitas kehidupan masyarakat. Dampak-dampak nyata yang dapat dianalisis dari korban perdagangan orang utamanya mengakibatkan mental dissorder (gangguan mental) karena efek trauma psikologis. Sebagian besar korban perdagangan manusia akan mengalami persoalan psikologis antara lain:

\section{Trauma}

Trauma merupakan masalah psikologis yang dialami individu atau kelompok atas perbuatan traumatis yang dialaminya. Jenis-jenis masalahnya dapat berupa tindak kekerasan, penyiksaan dan perbuatan represif lain yang memberikan tekanan psikologis.

Trauma adalah : "The essence of trauma is that it overwhelms the victim's psychological and biological coping mechanisms. This occurs when internal and external resources are inadequate to cope with the external threat.". ${ }^{20}$

\footnotetext{
${ }^{19}$ Ibid

20 Saporta, J. and B.A. van der Kolk, Psychobiological consequences of trauma, in Torture and its consequences: Current treatment approaches, M. Basoglu, Editor. 1992, Cambridge University Press: Cambridge.
} 
Warga NTT, khususnya para perempuan yang menjadi korban human trraficking mengalami trauma mendalam, keterasingan dan masalah sosial akibat pengalaman yang dialami. Masalahmasalah sosial berupa tekanan psikologis juga mempengaruhi aktivitas dan interaksi sosial.

\section{Kekerasan (violence) dan Korban Meninggal Dunia}

Akumulasi masalah dan penyiksaan yang dialami para korban perdagangan manusia telah menghadirkan berbagai masalah sosial. Khususnya persoalan yang dialami para korban human trafficking di NTT tidak hanya tekanan psikologis, namun lebih ekstrem menyebabkan korban meninggal dunia.

Polda NTT mencatat sekitar 1.667 calon Tenaga Kerja Wanita asal NTT yang dikirim keluar daerah secara ilegal dan menjadi korban Human Trafficking. Hingga tahun 2016, 37 warga NTT meninggal dunia ketika menjadi Tenaga Kerja Indonesia yang bekerja di luar Negeri. Kemudian, dari hasil komparasi data yang berbeda, menurut data Serikat Perempuan Indonesia (Seruni), terdapat 44 korban meninggal asal NTT akibat tersangkut kasus perdagangan orang. ${ }^{21}$

\section{c. Assessment dan Strategi Intervensi Pekerjaan Sosial}

\section{Assesment Penyebab}

Pada tahap ini, peran Pekerja Sosial adalah mencari atau mengumpulkan validitas informasi guna melakukan kajian analisis dalam menelusuri penyebab terjadinya human trafficking di
NTT. Pada bagian ini, Pekerja Sosial perlu mencari hubungan sebab-akibat sampai menimbulkan masalah. Untuk itu, penilaian yang hendak dibahas adalah, mengapa masalah human trafficking di NTT dapat terjadi dan menjadi masalah sosial.

Menjawab itu, penyebab utama sebagaimana dibahas pada isi pengantar, yaitu faktor-faktor ekonomi, kemiskinan dan pengangguran. Demi mendapat akses kesejahteraan, masyarakat berupaya meningkatkan taraf hidupnya melalui peningkatan pendapatan. Ketika kemiskinan menjadi isu sosial yang paling dominan, yang terjadi adalah polapola kejahatan cenderung tinggi, salah satunya kasus human trafficking.

\section{Assessment Masalah}

Pada tahap assessment (penilaian) masalah, Pekerja Sosial memberikan gagasan atau perspektif intervensi terhadap masalah yang ingin ditangani. Dalam konteks penilaian masalah, Pekerja Sosial perlu melakukan prinsip-prinsip kajian, penilaian sebelum menentukan langkah yang tepat untuk pencegahan (preventif). Pencegahan dapat dilakukan setelah kasus atau hubungan timbal balik antara penyebab dan masalah dipahami secara komprehensif. Langkah assessment ini penting untuk mensinergikan proses intervensi dan berupaya menghindari terjadinya masalah di kemudian hari melalui praktekpraktek pencegahan lewat intervensi. 
Pada aspek ini, Pekerja Sosial berperan menganalisa dan mengidentifikasi sumber-sumber masalah serta saran untuk praktek penanganannya sesuai konteks permasalahan. Dalam kaitan kasus human trafficking di NTT, assessment (penilaian) yang dapat dianalisis adalah terkait penyebab masalah yaitu lebih ditentukan oleh lingkungan dan minimnya akses sumber daya sosial (ekonomi, pendidikan). Kejahatan mudah terjadi akibat sumber-sumber primer masyarakat cenderung terabaikan, sehingga kondisi marginal dan ketersingkiran membuat produktifitas keberfungsian sosial tidak terakomodasi secara baik. Untuk itu, dalam konteks preventif, Pemerintah Daerah dan Pusat perlu singeri untuk mencari model bersama untuk mencegah kasuskasus perdagangan manusia di NTT. Misalnya, perangkat aturan atau penegakan hukum lebih inklusif sehingga hak-hak masyarakat dapat difasilitasi secara baik dan yang terpenting, para pelaku kejahatan ditindak tegas.

Kemudian, setelah para korban atau masyarakat yang terlibat diselamatkan dari rantai perdagangan manusia, langkah yang harus disiapkan adalah bagaimana proses mengelola sumber daya manusia dan menciptakan lapangan pekerjaan agar mereka tidak kembali menjadi korban. Ketika para korban telah kembali ke masyarakat, harus disiapkan sumberdaya sosial agar pengembangan kapasitas ekonomi dan kesejahteraan tercapai.

\section{Assesment Dampak}

Tahap assessment atau penilaian terhadap dampak, dilakukan setelah melalui fase penilaian penyebab (caused) dan analisis kasus atau masalah. Pekerja Sosial berperan memberikan solusi, melalui penentuan langkah-langkah dan intervensi praktis terkait penyelesaian masalah. Kasus human trafficking di NTT, dapat diidentifikasi dari beberapa aspek, sebagai resiko yang timbul dari kejahatan. Dampak-dampak yang dapat dijadikan bagian dari assessment ini adalah lebih didominasi faktor gangguan psikologis yang dialami korban (perempuan dan pekerja anak). Masalah ini menimbulkan berbagai persoalan lain, misalnya, keterasingan dari komunitas sosial, interaksi sosial dan terpuruknya status sosial. Untuk itu, Pekerja Sosial dalam mengkaji masalah ini perlu terlebih dahulu memahami pokok persoalan secara baik dan menyeluruh. Dalam konteks peran Pekerja Sosial untuk mengatasi dampak dari kasus ini, dapat dilakukan dengan metode intervensi terhadap korban, mencari tahu secara pasti keinginan dan potensi korban agar kembali berdaya di lingkungan sosialnnya. Misalnya, dapat digunakan sterngth based perspective, yaitu semaksimal mungkin menggali potensi yang dimiliki korban (sebagai penyandang masalah), kemudian meyakinkan secara mental dan psikologis bahwa korban mampu menyelesaikan masalahnya serta keluar dari keterasingan dan stigma masyarakat. Untuk mencapai itu, proses pelibatan (engagement) orang-orang terdekat (keluarga, tetangga) sebagai pihak yang penting dan sangat berpengaruh (significant others) terhadap proses penyembuhan dan pemberdayaan 


\begin{tabular}{|c|c|c|c|c|}
\hline $\begin{array}{c}\text { 118SHARE: SOCIAL WORK } \\
\text { JURNAL }\end{array}$ & VOLUME: 7 & NOMOR: 1 & HALAMAN: $1-129$ & $\begin{array}{l}\text { ISSN:2339 -0042 }(p) \\
\text { ISSN: } 2528-1577 \\
(e)\end{array}$ \\
\hline
\end{tabular}

korban yang sedang mengalami trauma.

\section{Intervensi Pekerjaan Sosial terhadap Human Trafficking}

Kasus human trafficking di NTT merupakan masalah sosial yang patut ditangani. Terkait konteks penanganan, ada beberapa kategori yang dapat digunakan sebagai pendekatan pemecahan masalah. Pendekatan Pekerjaan Sosial sebagai praktek profesional menawarkan konsep yang disebut intervensi dan assessment dalam bentuk strategi praktis mencari penyebab, menggali masalah, analisis, identifikasi dan solusi pemberdayaan bagi klien (orang yang membutuhkan bantuan) atau Penyandang Masalah Sosial.

Strategi penanganan Pekerja Sosial mengenal istilah Sistem Dasar, diperkenalkan oleh Allen Pincus dan Minahan. Pada tahun 1973, Pincus dan Minahan dalam karya Social Work Practice: Model and Method, merintis pendekatan penerapan analisis sistem pada praktek pekerjaan sosial. Asumsi dasarnya adalah, bahwa terdapat common core (inti pokok) mengenai keahlian dan konsep esensial dalam praktek pekerjaan sosial, yaitu melihat fakta berdasarkan interpretasi teoritis dan teori sistem. ${ }^{22}$

Pincus \& Minahan menggunakan empat sistem dasar Pekerjaan Sosial sebagai suatu pendekatan perubahan terencana.

a. Sistem Pelaksana Perubahan ( $a$ change agent system)

b. Sistem Client (a client system)

c. Sistem Sasaran (a target system)

d. Sistem Kegiatan (an action system)

22 "Assessment dalam Praktek Pekerjaan Sosial," dalam

http://kesos.unpad.ac.id/2010/04/29/assessment-

\section{Sistem Pelaksana Perubahan}

Sistem ini menjelaskan the change of agent system. Dalam penggunaannya untuk penanganan kasus human trafficking di NTT, pihak-pihak yang terlibat adalah Pekerja Sosial. Selain itu, adaapun Lembaga Swadaya Masyarakat (LSM) dan Non Governmental Organization (NGO) yang berkaitan dalam konteks mendukung penyelesaian masalah misalnya, UNODC dan IOM.

\section{Sistem Klien}

Menggambarkan relasi atau kesepakatan antara orang yang meminta pertolongan dengan agen perubahan, Target klien dalam masalah human trafficking di NTT adalah Pelaku human trafficking dan korban. Korban dan pelaku sama-sama diberikan pelayanan kemanusiaan oleh pihak-pihak yang terlibat dalam sistem pelaksana.

\section{Sistem Sasaran}

Sasaran dimaksud adalah pelaku Human Traffcking dan korban. Pertama, pelaku kejahatan perlu ditangani melalui pendalaman informasi, mencari alasan atau sebab mengapa yang bersangkutan melakukan tindakan kejahatan. Informasi dapat diperoleh melalui interview (misal: keluarga, tetangga, significant others),. Tujuan penanganan yang berbasis pada pelaku ini dilakukan untuk mencegah agar masalah tidak terus terjadi. Kedua, sasaran yang penting untuk dilayani adalah korban perdagangan manusia. Pendekatan yang dapat digunakan dalam

dalam-praktek-pekerjaan-sosial/, diakses tanggal 1 Januari 2017 


\begin{tabular}{|c|c|c|c|c|}
\hline $\begin{array}{c}\text { 118SHARE: SOCIAL WORK } \\
\text { JURNAL }\end{array}$ & VOLUME: 7 & NOMOR: 1 & HALAMAN: $1-129$ & $\begin{array}{l}\text { ISSN:2339 -0042 }(p) \\
\text { ISSN: 2528-1577 }(e)\end{array}$ \\
\hline
\end{tabular}

konteks praktek Pekerjaan Sosial yaitu strength based perspective, yang berprinsip pada pengembangan sumber daya yang ada dalam diri korban dan meyakinkan dia bahwa Ia memiliki potensi untuk keluar dari masalah trauma yang dialami.

\section{Sistem Kegiatan}

Lembaga atau organisasi yang bekerjasama dalam praktek assessment antara lain, Dinas Sosial, Psikolog, Psikiater dan juga keterlibatan Pemerintah Pusat seperti, Kementerian Sosial, Komnas HAM sebagai stakeholder yang berperan secara kelembagaan untuk memperkuat kapasitas pelayanan, advokasi, pemberdayaan bagi pelaku dan korban dalam rangka menyelesaikan masalah human trafficking di NTT.

\section{DAFTAR PUSTAKA}

Buku:

Farhana, Aspek Hukum Perdagangan Orang di Indonesia, Sinar Grafika, Jakarta, 2010.

Human Rights Watch, Seolah Saya bukan Manusia, 2008

Darwin Muhadjir, Pencegahan Migran dan Seksualitas, Yogyakarta : Center for Population and Policy Studies, Gadjah Mada University, 2003

Betz Diana, Thesis, Human Trafficking in Southeast Asia: Causes and Policy Implications, Naval Postgraduate School, California, 2009

Raharjo, ST. 2015. "Pekerjaan Sosial Generalis, Suatu Pengantar
Bekerja Bersama Organisasi dan Komunitas", Edisi Revisi Buku, Unpad Press,

Raharjo, ST. 2015. "Dasar Pengetahuan Pekerjaan Sosial", Buku, Unpad Press

Raharjo, ST., Taftazani, BM., Apsari, NC., Santoso, MB. 2016. "PANDUAN PRAKTIKUM

MIKRO

(Konseling dan Pengembangan Diri)". Buku . Unpad Press.

Raharjo, ST. 2015. "Assessment dan Wawancara dalam Praktik Pekerjaan Sosial dan Kesejahteraan Sosial”, Edisi Revisi Buku, Unpad Press

Tumenaite Ruta, Rise in human trafficking tied to poverty, international church conference participants say, Catholic Online, October 23, 2006

J. Saporta. And van der Kolk B.A., Psychobiological consequences of trauma, in Torture and its consequences: Current treatment approaches, M. Basoglu, Editor. 1992, Cambridge University Press: Cambridge

\section{Website:}

"Sex Slavery/Trafficking," dalam http://www.soroptimist.org/traffic king/faq.html, diakses tanggal 5 November 2016

"How Globalization Affects Transnational Crime," dalam http://www.cfr.org/transnationalcrime/globalization-affectstransnational-crime/p28403, diakses tanggal 5 November 2016

"Praktek Perdagangan Manusia dan Permasalahannya Ditinjau dari Sosiologi Hukum," dalam http://bp3akb.jabarprov.go.id/prak tek-perdagangan-manusia-danpermasalahannya-ditinjau-dari- 


\begin{tabular}{|c|c|c|c|c|}
\hline $\begin{array}{c}\text { 118SHARE: SOCIAL WORK } \\
\text { JURNAL }\end{array}$ & VOLUME: 7 & NOMOR: 1 & HALAMAN: $1-129$ & $\begin{array}{l}\text { ISSN:2339 -0042 }(p) \\
\text { ISSN: } 2528-1577(e)\end{array}$ \\
\hline
\end{tabular}

sosiologi-hukum/, diakses tanggal 3 November 2016

"Fellowship untuk Jurnalis: Liputan Investigasi Perdagangan Manusia," dalam http://jaring.id/id/enactivities/fello wship/fellowship-untuk-jurnalisliputan-investigasi-perdaganganmanusia/, diakses tanggal 4 November 2016

"Data Perdagangan Orang Oktober 2014," dalam http://www.irgsc.org/files/Oktobe r2014FINAL.pdf, diakses tanggal 3 November 2016

"1.667 Calon TKW Asal NTT Jadi Korban "Human Trafficking", dalam http://regional.kompas.com/read/2 016/08/23/09090061/1.667.Calon. TKW.Asal.NTT.Jadi.Korban.Hu man.Trafficking., diakses tanggal 3 November 2016

"Factors that Lead to Trafficking: Poverty," dalam

http://www.solidaritycenter.org/w

p-

content/uploads/2015/02/IndoTraf fickingCOMPILED-1.pdf, diakses tanggal 3 November 2016

"Ini Alasan Utama Maraknya Human Trafficking di NTT," dalam http://news.metrotvnews.com/rea d/2014/11/24/322744/ini-alasanutama-maraknya-humantrafficking-di-ntt, diakses tanggal 7 November 2016

"NTT, Surga Perdagangan Manusia," dalam http://floresbangkit.com/2015/01/ ntt-surga-perdagangan-manusia/, diakses tanggal 3 November 2016

"Praktek Perdagangan Manusia dan Permasalahannya Ditinjau dari Sosiologi Hukum," dalam http://bp3akb.jabarprov.go.id/prak tek-perdagangan-manusia-danpermasalahannya-ditinjau-dari- sosiologi-hukum/, diakses tanggal 3 November 2016

"KPPAD Bali Soroti Maraknya Kasus Human Trafficking di NTT," dalam

https://mikannews.com/2016/10/3 1/kppad-bali-soroti-maraknyakasus-human-trafficking-di-ntt/, diakses tanggal 7 November 2016

Raharjo, ST. "Assessment dalam Praktek Pekerjaan Sosial," dalam http://kesos.unpad.ac.id/2010/04/ 29/assessment-dalam-praktekpekerjaan-sosial/, diakses tanggal 1 Januari 2017 